\title{
Preparation and Characterization of Electrospun Human Hair Keratin / Poly (ethylene oxide) Composite Nanofibers
}

\author{
Yong Liu ${ }^{1}, \mathrm{Jia} \mathrm{Li}^{1}$, Jie Fan ${ }^{1}$, \\ Meng Wang ${ }^{2}$
}

\author{
${ }^{1}$ Key Laboratory of Advanced Textile Composites, Ministry of Education, School of Textiles, Tianjin Polytechnic Uni- \\ versity, 399 West Binshui Road, Tianjin, 300387, China \\ e-mail: liuyong@tjpu.edu.cn, fanjie@tjpu.edu.cn \\ 2 Tianjin Medical University Cancer Institute and Hospital, Huanhuxi Road, Hexi District, Tianjin, 300060, China \\ e-mail:wm@medmail.com.cn
}

\begin{abstract}
Keratin, as one of the most abundant proteins, has been widely used for bio-related applications due to its biocompatibility and biodegradability. In this study, keratin was extracted from human hair by sulphitolysis extraction method and then blended with poly (ethylene oxide) (PEO) at different proportions. The keratin/PEO mixture was dissolved in distilled water, and finally electrospun into composite nanofibers. The viscosity of keratin/PEO solution reduced with the increase of keratin mixture ratio. The viscosities of the solutions at mixture ratios of 30/70 and 40/60 keratin/PEO showed flow curves comparable with that of 6 and $4 \mathrm{wt} \%$ pure PEO solutions, respectively. The morphology, structure, and thermal property of the composite nanofibers were evaluated by Scanning Electron Microscope (SEM), Fourier Transform infrared spectroscopy (FTIR), and Differential Scanning Calorimetry (DSC), respectively. SEM analysis revealed that the morphologies of nanofibers were determined by the keratin content of keratin/PEO blend. Bead-free nanofibers could be found when the mixture ratio of keratin was below $70 \mathrm{wt} \%$ in the blend. FTIR analysis indicated that electrospinning process induced structural modifications in both the crystalline microstructure of pure PEO and keratin chains with a planar conformation with respect to the helical conformation. Thermal behavior of the keratin/PEO composite nanofibers showed that a high draw occurred in the electrospinning process causing the protein chains a less complex super-molecular reorganization that denatured at lower temperatures. The keratin/PEO composite nanofibers has potential for biomaterials such as cell culture substrate.
\end{abstract}

Keywords: Electrospinning; Human hair keratin; PEO; Nanofibers; FTIR; DSC.

\section{INTRODUCTION}

Electrospinning, which was paid much attention by many researchers, is an interesting and unique technique for producing ultrafine and nano- fibers with diameter in the range from several micrometers down to tens of nanometers [1-3]. There are a wide range of polymers that have been produced nanofibers by electrospinning over the last three decades [4]. The apparatus used for electrospinning includes a high voltage DC supply, a syringe pump with capillaries for carrying the solution from the syringe or pipette to the spinneret, and a grounded metal collector.

Among polymer nanofibers, the protein polymer nanofibers, which are extracted from silk fibroin, collagen, fibrinogen and gelatin, are used as wound dressings, drug delivery platforms, tissue engineering scaffolds and so forth due to their good biocompatibility and degradability, high specific surface area and high porosity [5-9]. Recently, many researchers found that keratin-based biomaterials had excellent properties for regenerative medicine applications and scaffolds for cell cultivation [10-12]. However, the poor mechanical properties of regenerated keratin hinder its processability and restrict its practical applications [13-15].

In order to overcome the imperfections of pure keratin-based biomaterials, keratin was usually blended with appropriate polymers, such as poly (ethylene oxide) (PEO), for composite materials with better structural properties. PEO was selected as an ideal polymer blended with keratin by many researchers due to its good biocompatibility, low toxicity, water solubility, green and safe. Recently, a few of publications 
focused on how to fabricate keratin / PEO blend nanofibers and their applications in the field of biomaterials. However, there is still a lack of a deep understanding of the properties of keratin / PEO nanofibers for further applications.

In this work, keratin/PEO aqueous solutions with different mixture ratios were prepared and electrospun into keratin /PEO composite nanofibers. The morphology, structure and thermal behavior of the nanofibers were investigated by scanning electron microscopy (SEM), Fourier transform infrared (FTIR) spectroscopy, and differential scanning calorimetry (DSC).

\section{MATERIALS AND METHODS}

\subsection{Materials and Characterization}

Human hair from a 3-year-old girl was used. Urea and sodium disulfite $\left(\mathrm{Na}_{2} \mathrm{~S}_{2} \mathrm{O}_{6}\right)$ were purchased from Tianjin recovery technology development Co, LTD. Sodium dodecyl sulfate (SDS) was supplied by Tianjin recovery fine chemical industry research institute. Petroleum ether was obtained from Tianjin rare chemical reagent factory. PEO, molecular weight of 400,000, was supplied by Shanghai Liansheng chemical Co, LTD. All the chemicals were used without further purification.

A desktop scanning electron microscope (SEM, TM-1000, Hitachi, Japan), a Fourier transform infrared spectrometer (TENSOR 37 Bruker, Germany) and a differential scanning calorimeter (DSC200F3, Metzsch, Germany) were used to characterize the morphologies, structure and property of the keratin / PEO composite nanofibers. All rheological measurements were carried out using a Rheometer (Bohlin CVO 100D, Malvern, UK).

\subsection{Preparation of keratin / PEO solution}

Generally, keratin was extracted from human hair by sulphitolysis extraction method [5]. In our experiments, human hair was firstly cleaned by Soxhlet extraction with petroleum ether for removing fatty matter, then washed with distilled water, dried at room temperature for $24 \mathrm{~h}$, and finally cut into $5 \mathrm{~mm}$ length.

A $6 \mathrm{~g}$ sample of above human hair was immersed in $200 \mathrm{~mL}$ of aqueous solution containing $7 \mathrm{~mol} / \mathrm{L}$ urea, $2 \mathrm{wt} \% \mathrm{SDS}$, and $5 \mathrm{wt} \% \mathrm{Na}_{2} \mathrm{~S}_{2} \mathrm{O}_{6}$. Then the mixture was poured into a round-bottom flask and heated to $95^{\circ} \mathrm{C}$ shaking for $4 \mathrm{~h}$. The obtained mixture was filtered through a stainless-steel mesh, and then dialyzed against $3 \mathrm{~L}$ of distilled water, with cellulose tubing having a molecular weight cutoff of 10000 14000Da for $36 \mathrm{~h}$, changing distilled water every 12 hours. The resulting dialysis fluid was filtered again through a stainless-steel mesh and then stirred with magnetic stirrers. The human hair keratin concentration of the dialyzate was about $6 \mathrm{wt} \%$.

The keratin / PEO blend solutions were prepared by adding different amounts of PEO, which was dissolved in distilled water at the room temperature for about $12 \mathrm{~h}$, into keratin aqueous solution with $7 \mathrm{wt}$. $\%$ of total polymeric concentration.

\subsection{Electrospinning of keratin / PEO composite nanofiber}

About $5 \mathrm{~mL}$ of the mixed polymer solution was placed in a syringe linked to a capillary pipe with a metallic tip. The tip was positively charged by a DC high voltage generator (DW-P303-1AC, Tianjin Dongwen Co., China). A rotating grounded stainless cylinder was used as collector. In electrospinning process, the distance between the syringe tip and the collector was fixed at $15 \mathrm{~cm}$ to ensure a complete evaporation of the solvent. The applied voltages were adjusted from 10 to $30 \mathrm{kV}$ and a constant volume flow rate was $0.5 \mathrm{ml} \mathrm{min}^{-1}$.

\section{RESULTS AND DISCUSSION}

\subsection{Viscosity of keratin / PEO solution}

In order to investigate the influence of keratin content in keratin / PEO solution on the morphology of nanofibers, PEO solution was mixed in keratin solution with different mixture ratio at 30:70, 40:60, 50:50,60:40, 70:30, 80:20, 90:10. The viscosity of blended solution was obviously different with different mixture ratio. As our previous literature [16-18], the solution viscosity plays an important role in determining the morphology of nanofibers. Fig.1 shows the dynamic viscosities of the keratin/PEO solutions and of 4, 6, and $7 \mathrm{wt} \% \mathrm{PEO} /$ water solution. It can be found that all the viscosities reduce with increasing the shear rate in a logarithmic plot, suggesting that the disentanglement rate exceeds the rate of entanglement formation at 
higher values of shear rate [13]. With keratin content in blended solution increasing, the solution viscosity reduces. The keratin/PEO solutions at mixture ratios of 30:70 and 40:60 shows flow curves comparable with 6 and $4 \mathrm{wt} \%$ pure PEO solutions, respectively. The reason may be due to short keratin molecules leading to reduction of the entanglement concentration.
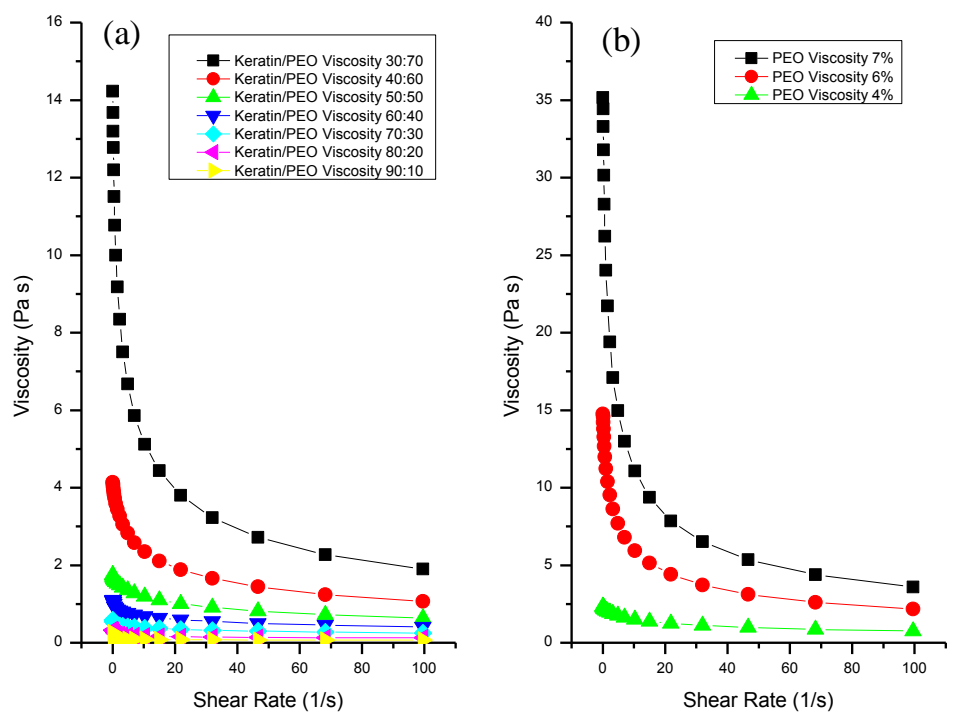

Figure 1: Viscosity flow curves of (a) keratin/PEO solutions and (b) pure PEO solution.

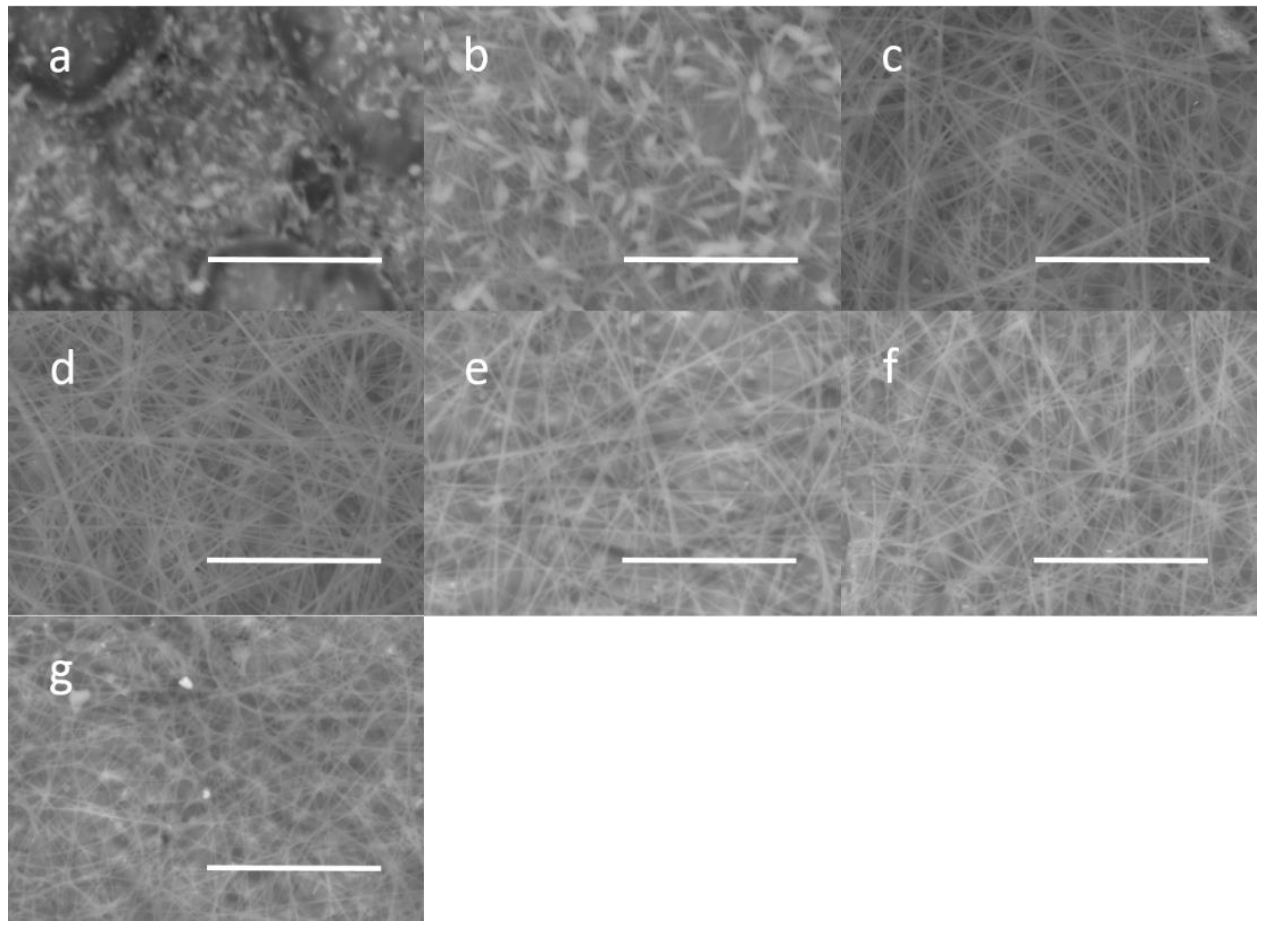

Figure 2: Scanning electron micrographs of keratin/PEO nanofibers: (a) 90/10; (b) 80/20; (c) 70/30; (d) 60/40; (e) 50/50; (f) 40/60; (g) 30/70. The bars are $30 \mu \mathrm{m}$.

\subsection{Morphology of keratin/PEO nanofibers}

Figure 2 shows the SEM micrographs of morphologies of obtained keratin/PEO nanofibers with different polymer mixture ratios. The mixture solution of keratin/PEO at 90:10 showed very poor electrospinnability 
and only beads and droplets were formed (Fig. 2a). The formation of beaded fibers has been observed widely in the solution with $80 \mathrm{wt} \%$ of keratin (Fig.2b) while the beads were spindle-shaped, suggesting stretching occurred. The reason may be that the low viscosity of the solution that gives rise breaking of the jet at the capillary tip. The maximum keratin concentrations for the formation of bead-free nanofibers were $70 \mathrm{wt} \% \mathrm{in}$ the blends. The obtained products were bead-free nanofibers when the keratin/PEO mixture ratios were $70 / 30,60 / 40,50 / 50,40 / 60$, and 30/70, as shown in Fig.2c-g. The results showed that the increase of the solution viscosity with the keratin content decreasing (as shown in Figure 1) resulted in bead-free nanofibers production. In other words, when the PEO amount in the blends is higher, there are sufficient molecular chain entanglements to prevent breaking of the electrically driven jet and form easily continuous nanofibers.

\subsection{FTIR spectra}

Infrared spectroscopy has been extensively applied in the study of the molecular conformation of polymers. There are several characteristic absorption bands known as amide A $\left(3286 \mathrm{~cm}^{-1}\right)$, amide B $\left(3056-3075 \mathrm{~cm}^{-1}\right)$, amide I (1600-1700 $\left.\mathrm{cm}^{-1}\right)$, amide II (1480-1580 $\left.\mathrm{cm}^{-1}\right)$ and III $\left(1220-1300 \mathrm{~cm}^{-1}\right)$ in keratin protein. The recorded FTIR spectra of untreated hair and keratin powders were depicted in Fig. 3(d). Keratin powders produced by freezing and lyophilization showed great differences in the magnitude of the spectrum between $1700 \mathrm{~cm}^{-1}$ and $1000 \mathrm{~cm}^{-1}$. The main difference is that the keratin had more area than the human hair, which could be due to the reduction of solution that caused the break of the disulfide bond and finally resulted in the increase of numbers with amide I, amide II, and amide III. The bands at $1656 \mathrm{~cm}^{-1}$ assigned to amide $\mathrm{I}(\mathrm{C}=\mathrm{O})$ stretching, the $1539 \mathrm{~cm}^{-1}$ peak assigned to deformation vibration in $\mathrm{NH}$-plane and $1284 \mathrm{~cm}^{-1}$ associated with the amide III.
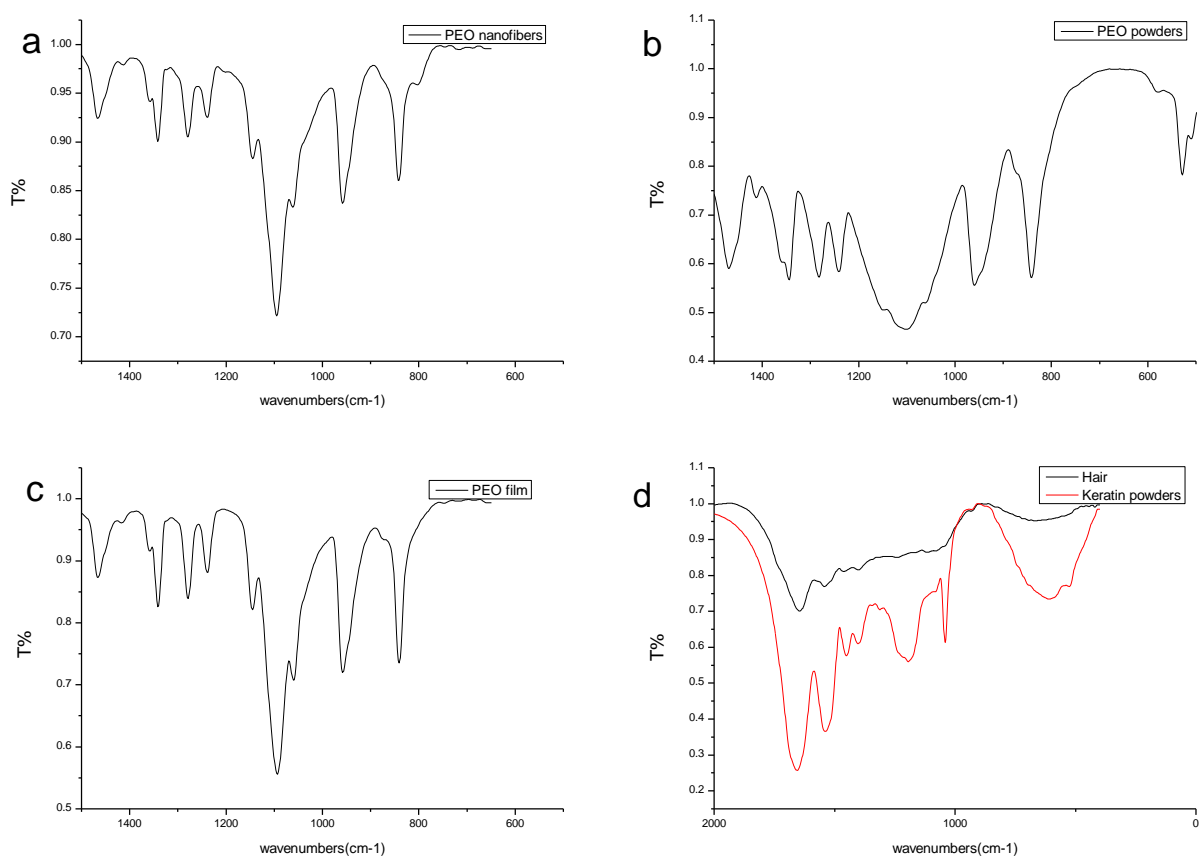

Figure 3: FTIR spectra of PEO nanofibers from electrospinning (a), pure PEO powders (b), PEO film (c), keratin powers and human hairs (d).

Fig. 3(a, b, c) shows that the FTIR spectra obtained from pure PEO nanofibers, PEO powders and PEO film, respectively. The presence of the crystalline PEO phase is confirmed by the triplet peak of the CO-C stretching vibration at $1145.65,1093.57$, and $1060.78 \mathrm{~cm}^{-1}$, with the highest absorption at $1093.57 \mathrm{~cm}^{-1}$. Changes in the intensity, shape, and position of the C-O-C stretching absorptions indicate conformational structures change, as reported by Antonio et al [19]. The intensities of the peaks at 1145.65 and $1240.15 \mathrm{~cm}^{-1}$ are the result of the planar conformation increasing in electrospun samples, but the peaks related to the helical conformation at $1060.78,958.56$, and $840.91 \mathrm{~cm}^{-1}$ decrease. As observed also in the infrared spectroscopy of PEO powders (Fig. 3b), the helical conformation at 1060.78, 958.56, and $840.91 \mathrm{~cm}^{-1}$ disappear. These results suggest that the electrospinning process promotes the planar conformation of PEO and the powder process changes the conformation of PEO. 
Fig. 4 shows the curve-fitted amide I region of keratin/PEO (60/40) composite nanofibers and film obtained from drying keratin/PEO solution in drying oven. The amide $\mathrm{I}$ absorption owing to the $\mathrm{C}=\mathrm{O}$ stretching vibration is particularly sensitive to the secondary structure of the keratin. Since the amide I band of keratin is not disturbed by the PEO absorptions for falling in a region, it can be used to study the structural conformation of keratin chains in the composite nanofibers and the composite film. The secondary structure of keratin in films and nanofibers were compared by the curve fitting of the amide I band in Fig.4 (a, b). The signal band at $1650 \mathrm{~cm}^{-1}$ is characteristic of the $\alpha$ - helical structures [20], while the band $1623 \mathrm{~cm}^{-1}$ is characteristic of $\beta$-sheet structure. The bands between 1677 and $1687 \mathrm{~cm}^{-1}$ are observed for disordered conformations. However, in contrast to the former, the film shows an increase of the band area related to $\beta$ sheet structure along with a decrease of the $\alpha$-helix band area [21]. This is attributed to structural modification of keratin caused by the intense filament strain due to the strong drawing forces occurred in the electrospinning process.
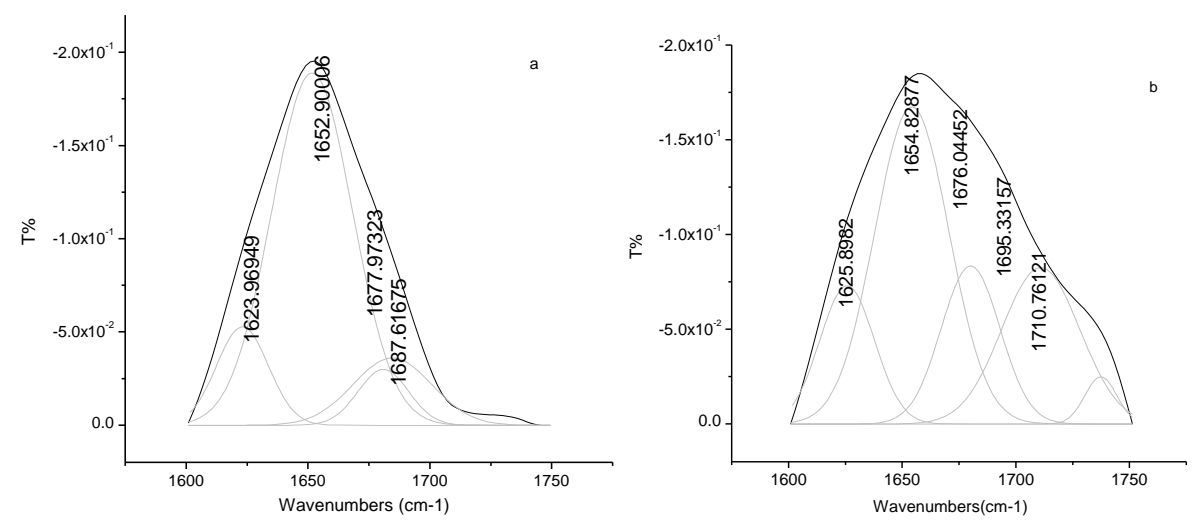

Figure 4: Curve-fitted amide I region of keratin/PEO 60/40 (a) composite nanofibers and (b) composite film.
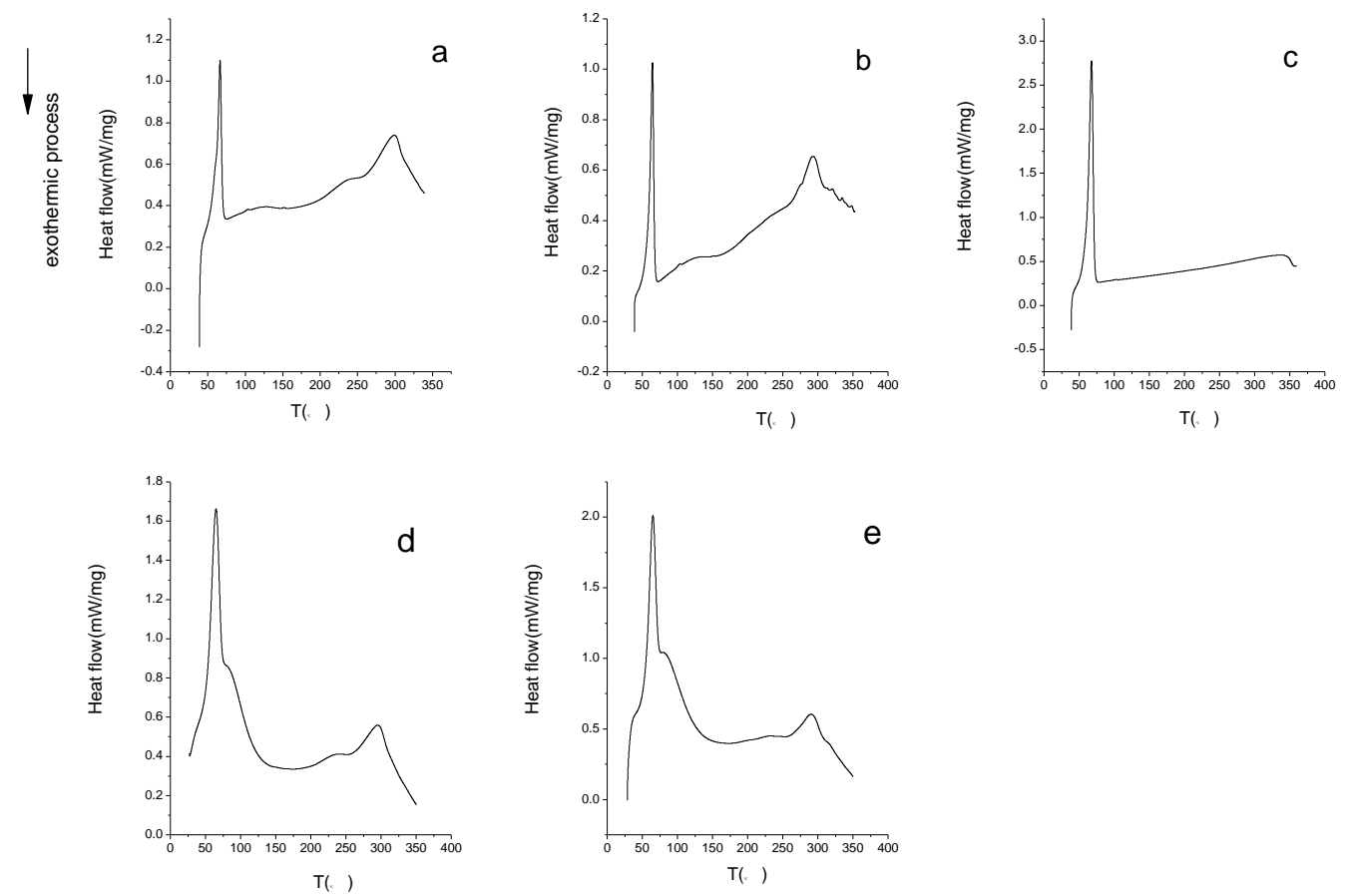

Figure 5: DSC curves of 60/40 keratin/PEO film (a, d), 60/40 keratin/PEO nanofibers (b, e) and pure PEO powders(c).

\subsection{Thermal behavior}

In order to study the structural changes occurred in the electrospinning process, the DSC traces of the 60/40 keratin/PEO film (a, d) , 60/40 keratin/PEO nanofibers (b, e) and pure PEO powders are reported in Figure 5. 
The DSC curves of keratin/PEO composite samples (films and nanofibers) are respectively shown in Fig.5 (a, b, d, e). In order to compare with the composite films and nanofibers, DSC curve of pure PEO powders was also reported that the melting event occurred at $60.7-71.5{ }^{\circ} \mathrm{C}$ temperature range, showed $136 \mathrm{~J} / \mathrm{g}$ for the melting enthalpy, as illustrated in Fig. 5c. The endothermic overlapped peaks values ranging from 55 ${ }^{\circ} \mathrm{C}$ to $80{ }^{\circ} \mathrm{C}$ are due to the fusion of the PEO crystalline phase and to the evaporation of water, especially absorbed by keratin [13], as shown in Fig.5 (d, e). The endothermic peak between 60 and $70^{\circ} \mathrm{C}$ decreased is mainly due to water disappeared during the process of eliminating thermal history (see Fig. 5a, b). The presence of peak of protein denaturation followed by protein degradation [22], which falls at $298^{\circ} \mathrm{C}$ in the composite film, shifts to a lower temperature of $293^{\circ} \mathrm{C}$ in the electrospun sample, was observed in the range of $200-350^{\circ} \mathrm{C}$. It should be pointed out that the high draw, given by the electrospinning process, leading the protein chains to a less complex super-molecular reorganization that denatures at lower temperatures [23].

\section{CONCLUSIONS}

The keratin / PEO blend solutions were prepared by blending in different proportions with PEO in aqueous solutions based on extracting keratin from human hair using sulphitolysis extraction method. Keratin/PEO composite nanofibers can be produced by electrospinning process. The results showed that the maximum keratin concentrations for the formation of bead-free nanofibers were $70 \mathrm{wt} \%$ in the blends. FTIR suggested that the electrospinning process promoted the planar conformation of PEO and keratin chains with a more developed planar conformation with respect to the helical conformation. DSC analysis indicated that a high draw by the electrospinning process caused the protein chains a less complex super-molecular reorganization that denatured at lower temperatures.

A further work includes increasing the blend proportion of keratin in electrospun composite nanofibers, improving the mechanical properties and the water stability of keratin/PEO composite nanofibers, and strengthening the application of keratin/PEO composite nanofibers as cell culture substrate.

\section{ACKNOWLEDGMENTS}

This work is supported by National Natural Science Foundation of China under Grant no. 51003073, Foundation for the Author of National Excellent Doctoral Dissertation of China (no. 201255), Program for New Century Excellent Talents in University (NCET-12-1063), National Science Foundation of Tianjin (no. 14JCYBJC17600), and Ningbo Natural Science Foundation (no. 2013A610016).

\section{BIBLIOGRAPHY}

[1] KI, C. S., BAEK, D. H., GANG, K. D., et al., "Characterization of gelatin nanofiber prepared from gelatin-formic acid solution", Polymer, v. 46, n. 14, pp. 5094-102, 2005.

[2] MIN, B-M., LEE, G., KIM, S. H., et al., "Electrospinning of silk fibroin nanofibers and its effect on the adhesion and spreading of normal human keratinocytes and fibroblasts in vitro", Biomaterials, v. 25 , n. 7 , pp. 1289-97, 2004.

[3] OHGO, K., ZHAO, C., KOBAYASHI, M., et al., "Preparation of non-woven nanofibers of Bombyx mori silk, Samia cynthia ricini silk and recombinant hybrid silk with electrospinning method", Polymer, v. 44, n.3, pp. 841-846, 2003.

[4] RAGHAVAN, P., LIM, D-H., AHN, J-H, et al., "Electrospun polymer nanofibers: The booming cutting edge technology", Reactive and Functional Polymers, v. 72, n. 12, pp. 915-930, 2012.

[5] BUCHKO, C. J., CHEN, L. C., SHEN, Y., et al., "Processing and microstructural characterization of porous biocompatible protein polymer thin films". Polymer, v.40, n. 26, pp.7397-7407, 1999.

[6] HUANG, Z-M, ZHANG, Y. Z., RAMAKRISHNA, S., et al. , "Electrospinning and mechanical characterization of gelatin nanofibers". Polymer, Vol. 45,n. 15, pp.5361-5368, 2004.

[7] JIN, H. J., FRIDRIKH, S. V., RUTLEDGE, G. C., et al., "Electrospinning Bombyx mori silk with poly(ethylene oxide)", Biomacromolecules, v. 3, n. 6, pp. 1233-1239, 2002.

[8] VERRECK, G., CHUN, I., ROSENBLATT, J., et al., "Incorporation of drugs in an amorphous state into electrospun nanofibers composed of a water-insoluble, nonbiodegradable polymer", Journal of controlled release : official journal of the Controlled Release Society, v. 92, n. 3, pp. 349-360, 2003.

[9] ZENG, J., XU, X., CHEN, X., et al., "Biodegradable electrospun fibers for drug delivery". Journal of controlled release : official journal of the Controlled Release Society, v. 92, n. 3, pp. 227-231, 2003.

[10] FURTH, M.E., ATALA, A., VAN DYKE, M.E., "Smart biomaterials design for tissue engineering and regenerative medicine", Biomaterials, v. 28, pp. 5068-5073, 2007. 
[11] TACHINABA, A., KANEKO, S., TANABE, T., et al., "Rapid fabrication of keratin-hydroxyapatite hybrid sponges toward osteoblast cultivation and differentiation", Biomaterials, v. 26, pp. 297-302, 2005.

[12] HAMASAKI, S., TACHINABA, A., TADA, D., et al., "Fabrication of highly porous keratin sponges by freeze-drying in the presence of calcium alginate beads", Material Science and Engineering: C, v. 28, pp. 1250-1254, 2008.

[13] TONIN, C., ALUIGI, A., VARESANO, A., et al., "Keratin-based Nanofibers", In: Ashok Kumar (eds), Nanofibers, chapter 7, India, Published by Intech, February 2010.

[14] ALUIGI, A., VARESANO, A., MONTARSOLO, A., et al. "Electrospinning of keratin/poly(ethylene oxide)blend nanofibers", Journal of Applied Polymer Science, v. 104, n. 2, pp. 863-870, 2007.

[15] CHEN, Q., LIANG, S., THOUAS, G. A., "Elastomeric biomaterials for tissue engineering", Progress in Polymer Science, v. 38, n. 3-4, pp. 584-671, 2013.

[16] LIU Y., HE, J-H., YU, J-Y., et al., "Controlling Numbers and Sizes of Beads in Electrospun nanofibers", Polym Int, v. 57, pp. 632-636, 2008.

[17] LIU, Y., DONG, L., FAN, J.,et al., "Effect of Applied Voltage on Diameter and Morphology of Ultrafine Fibers in Bubble Electrospinning”, J Appl Polym Sci, v. 120, pp.592-598, 2011.

[18] LIU, Y., LIANG, W., SHOU, W., et al., "Effect of Temperatureon the Crater-like Electrospinning Process", Heat Transfer Research, v. 44, pp. 447-454, 2013.

[19] PEREIRA, A. G. B., GOUVEIA, R. F., DE CARVALHO, G. M., et al., "Polymer blends based on PEO and starch: Miscibility and spherulite growth rate evaluated through DSC and optical microscopy", Materials Science and Engineering: C, v. 29, n. 2, pp. 499-504, 2009.

[20] CHEATUM, C. M., TOKMAKOFF, A., KNOESTER, J., "Signatures of beta-sheet secondary structures in linear and two-dimensional infrared spectroscopy", The Journal of chemical physics, v. 120, n. 17, pp. 8201-8215, 2004.

[21] GOORMAGHTIGH, E., RUYSSCHAERT, J. M., RAUSSENS, V., "Evaluation of the information content in infrared spectra for protein secondary structure determination", Biophysical journal, v. 90, n. 8, pp. 2946-2957, 2006.

[22] SPEI, M., HOLZEM, R., "Thermoanalytical investigations of extended and annealed keratins", Colloid \& Polymer Sci, Vol. 265, n. 11, pp. 965-970, 1987.

[23] ASAO, Y., KIYOSHI, Y., "Formation and Properties of Wool Keratin Films and Coatings", In: Gennadios, A. (eds), Protein-Based Films and Coatings, Chapter 10, CRC Press, 2002. 